\title{
An Epidemiological Study on Influenza A(H1N1) in Makkah
}

\author{
Nezar H. Khdary1,2, Muhammed A. Alalem², Abdulhafiz M. Turkistan³, Saad S. Alghamdi ${ }^{3}$ \\ ${ }^{1}$ King Abdulaziz City for Science and Technology, Riyadh, KSA \\ ${ }^{2}$ Preventive Health Affairs and Infectious Diseases Control Department, Directorate of Health Affairs, \\ Makkah, KSA \\ ${ }^{3}$ Primary Health Care Affairs and Diseases Control, Makkah, KSA \\ Email: nkhdary@kacst.edu.sa
}

Received 10 October 2014; revised 17 November 2014; accepted 28 November 2014

Copyright @ 2014 by authors and Scientific Research Publishing Inc.

This work is licensed under the Creative Commons Attribution International License (CC BY).

http://creativecommons.org/licenses/by/4.0/

(c) (i) Open Access

\section{Abstract}

The flu pandemic is a global outbreak of a new strain of influenza A virus subtype H1N1, termed Pandemic H1N1/09 virus by the World Health Organization (WHO), which was first identified in April 2009. The disease has also been termed novel Influenza A(H1N1) and 2009 H1N1 flu by the US Centers for Disease Control and Prevention (CDC), and is commonly known as swine flu. The main strain of the virus has been termed A/California/07/2009 (H1N1) by scientists. This study was conducted to describe the epidemiology of influenza A(H1N1) infections in KSA during 2009. A descriptive study was carried out among attendants at hospitals and primary health care centers in Makkah during 2009, irrespective of age and sex. The data were collected by interviewing suspected persons using a pre-designed questionnaire, clinical examination, and specific laboratory investigation. A total of $\mathbf{1 1 3 8}$ subjects were included in the study. Among the study population, $25 \%$ of the cases between 15 and 24 years old were found positive for influenza A(H1N1) by PCR technique. Although a significant population was affected by influenza A(H1N1) during 2009 in Makkah, the efforts and steps taken by health authorities at all levels-especially those in Directorate of Health Affairs of Makkah-helped to avert the mortality associated with the H1N1 influenza among the residents and those coming for Umrah and Hajj to Makkah by providing and timely diagnosis.

\section{Keywords}

Influenza, H1N1, Swine Flu, Makkah

\section{Introduction}

A swine origin influenza A virus epidemic was initiated in April 2009 with the first cases appearing in Mexico 
and the United States. The virus acquired rapid transmissibility and pandemic potential with more than 340,000 laboratory-confirmed cases and more than 4100 deaths reported to the World Health Organization (WHO) as at September 27, 2009. Given the evidence of sustained community-level outbreaks of novel Influenza A(H1N1) in more than one WHO region, WHO designed the virus as "pandemic influenza A(H1N1) 2009 virus" [1].

The outbreak was first observed in Mexico, with evidence that there had been an ongoing epidemic for months before it was officially recognized [2]. The Mexican government soon closed most of Mexico City's public and private offices and facilities to contain the spread of the virus. As the virus quickly spread globally, clinics were overwhelmed by testing and treating patients, and the WHO and the US Centers for Disease Control and Prevention (CDC) eventually stopped counting all cases and focused instead on tracking major outbreaks. On June 11, 2009, the WHO declared the outbreak to be a pandemic [3].

Only mild symptoms are experienced by the overwhelming majority of victims, but there are exceptions. Some persons are in higher risk groups, such as those with heart disease, asthma, obesity, diabetes, children with neurodevelopmental conditions [4] [5], or pregnant women, and immune compromised individuals [6]. However, a small subset of previously healthy young adults rapidly developed severe pneumonia, typically 3 to 5 days after the initial onset of symptoms with rapid deterioration progressing to respiratory failure within 24 hours, requiring intensive care and ventilation support [7]. Like other influenza viruses, swine flu is typically contracted by inhaling air that has been contaminated by an infected person coughing or sneezing, or by touching one's nose or mouth with hands that have previously touched contaminated surfaces and have not been disinfected. Symptoms, which last up to a week, are similar to those of seasonal flu, and can include fever, sneezing, sore throat, cough, headache, and muscle or joint pains. To avoid spreading the infection, the CDC recommended that those with symptoms stay home from school, work, and crowded settings. Wearing facial masks was not recommended except in health care settings [8]. On the other hand, the swine flu outbreak has led to numerous precautionary school closures in several countries. Rather than closing schools, in August 2009 the CDC recommended that students and school workers with flu symptoms should stay home for either seven days total, or until 24 hours after symptoms subside; whichever is longer [9]. The CDC also recommended that colleges should consider suspending fall 2009 classes if the virus began to cause severe illness in a significantly larger share of students than the previous spring. Different countries adopted strategies to control the spread of the novel influenza $\mathrm{A}(\mathrm{H} 1 \mathrm{~N} 1)$ virus, especially among the schools, by promoting hand hygiene, vaccination priority, and school closures if required [10]-[16].

The city of Makkah is situated to the west of The Kingdom of Saudi Arabia (KSA), and has an influx of people from multiple nationalities, since it is the holy pilgrimage site for Muslims all over the world. Traditionally, the KSA, its leadership, health authorities, and all people have committed to serving the pilgrims of the Holy places in Makkah and Medinah ensuring that guests can perform their rituals with ease and dignity. It is estimated that between 2 and 3 million pilgrims from all over the world perform Hajj annually, which, being the largest gathering of people, facilitates the spread of various infectious agents including viruses [17]. This study was conducted to describe the epidemiology of influenza A(H1N1) infections in KSA among residents, citizens, and students in Makkah city during 2009.

\section{Methodology}

\subsection{Descriptive Study}

The study population in Makkah, KSA, during 2009 included all age groups without any discrimination on the basis of age, sex, or ethnicity. The standard WHO case definition for Influenza A(H1N1) was used for inclusion as the study subject [18]. The study was carried out on subjects reporting to hospitals and primary health care centers in Makkah with signs and symptoms of influenza as per the case definition. The subjects were enrolled by non-probability convenience approaches and interviewed using a pre-designed questionnaire, a clinical examination, and specific laboratory investigations. All the studied persons were subjected to a clinical examination, a chest X-ray, and microbiological investigations.

\subsection{Specimen Collection and Transportation}

From all the cases, the specimens were collected either by nasopharyngeal swab, nasal aspirate, or a combination of nasopharyngeal and/or pharyngeal swab. After collection, the swabs were immediately transferred to a 
sterile vial of a viral transport medium and cooled by ice packs at $4^{\circ} \mathrm{C}$. Samples were transported into the lab in closely sealed containers. Restricted protective measures were undertaken during sample collections, transportation, and processing.

\subsection{Nucleic Acid Extraction}

Nucleic acid extraction was performed according to the manufacturer's instructions using the High Pure Viral Nucleic Acid Kit (Roche). In this process, $200 \mu \mathrm{L}$ from each sample was added to the pre-pared working solution (200 $\mu \mathrm{L}$ binding buffer supplemented with poly (A) and $50 \mu \mathrm{L}$ proteinase $\mathrm{K}$ ). The tubes were mixed immediately and incubated at $72^{\circ} \mathrm{C}$ for $10 \mathrm{~min} .100 \mu \mathrm{L}$ of binding buffer was then added and the contents were centrifuged for $1 \mathrm{~min}$ after being transferred to the high pure filter. Following serial washes with removal and wash buffers according to the kit instructions, RNA was eluted with $50 \mu \mathrm{L}$ elution buffer.

\subsection{Real-Time PCR}

Real time PCR was carried out using $20 \mu \mathrm{L}$ reaction volumes with $5 \mu \mathrm{L}$ master mix prepared using the Real Time Ready kit (Influenza A/H1N1 Detection Set, Roche, USA) and $5 \mu \mathrm{L}$ of sample RNA. The method was established according to the recommendation of the CDC for laboratories to detect H1N1. Positive and negative control/standards were used according to the prescribed CDC protocol. The amplification process was done using Light Cycler 2.0 (Roche) under the following PCR conditions: reverse transcription (1 cycle) at $55^{\circ} \mathrm{C}$ for 8 min; initial denaturation (one cycle) at $95^{\circ} \mathrm{C}$ for $30 \mathrm{sec}$; the amplification process was done in 45 cycles including denaturation at $95^{\circ} \mathrm{C}$ for $1 \mathrm{sec}$, annealing at $60^{\circ} \mathrm{C}$ for $20 \mathrm{sec}$, and extension at $72^{\circ} \mathrm{C}$ for 1 sec. The cooling step was done at $40^{\circ} \mathrm{C}$ for $30 \mathrm{sec}$. Results were displayed using the absolute qualification mode.

\subsection{Data Analysis}

Data were compiled and analyzed using MS-Excel to calculate the frequencies as percentages. The data were compared among the citizens, the residents, and the students. Among the students, the percentage of positive cases with different nationalities was also calculated.

\section{Results}

A total of 1138 subjects were studied during the study period. The majority (81\%) of the persons suspected to have influenza $\mathrm{A}(\mathrm{H} 1 \mathrm{~N} 1)$ among the study population were between 5 and 45 years old. Among these, the maximum percentage (24.8\%) of persons were between 15 and 24 years old, while 20\% were between 10 and 14 years old, and 14\% were between 25 and 34 years old. Among the citizens and residents, most of the suspected cases were between 15 and 44 years old (60.4\%), while among the students, most of the cases were between 5 and 24 years old (91.8\%) representing preparatory, primary and secondary stages. Around 6\% of the suspected cases for Influenza A(H1N1) in schools were the employees. The details are given in (Table 1).

The results of the PCR test showed that, the citizens and residents had the maximum percentage of PCR-positive cases in the 15 - 34 years age group (49.3\%) among other categories. In the student group, the highest percentage of PCR-positive cases was between 5 and 24 years (93.3\%). The cumulative PCR positivity among the study subjects was the highest among the 15 - 24 years age groups (24.6\%). Nearly half of the PCR-positive cases for Influenza A(H1N1) students (48\%) were in the primary school age group (10 - 14 years) and $26 \%$ (5 9 years) age group; while students in the secondary school age groups represented (19\%) of PCR-positive for Influenza $\mathrm{A}(\mathrm{H} 1 \mathrm{~N} 1)$, which was the lowest percentage among other school stages. Employees in schools accounted for $8 \%$ of PCR-positive cases for Influenza A(H1N1). The cases were compiled by age distribution through grouping the cases at 5-year intervals. Table 2 shows the details of distribution. Figure 1 illustrates the percentage of total distribution among the age groups.

The sex distribution shows that among the residents and citizens, males accounted for 55\% of the cases while $45 \%$ were females with a male-to-female ratio of 1:1.22. Similarly, in the student groups, the male-to-female ratio was 1:1.1. The details are given in (Table 3). The analysis of PCR results by gender revealed that overall, around $58 \%$ of the males were positive while around $42 \%$ were females (Table 4 ). More than one-half (55\%) of the persons suspected for Influenza A(H1N1) among the population were males and the rest were females (45\%). This ratio was about the same for students where males were $52 \%$ and the rest were females (48\%). There was 
Table 1. Distribution of the study population by age group for Influenza A(H1N1) among the study population.

\begin{tabular}{cccc}
\hline Characteristic age in years & Citizens \& residents \% & Students \% & Citizens, residents, \& students \% \\
\hline$<5$ & 12.3 & 0.0 & 7.0 \\
$5-9$ & 5.2 & 22.3 & 12.3 \\
$10-14$ & 4.8 & 41.5 & 20.4 \\
$15-24$ & 22.5 & 28.1 & 24.8 \\
$25-34$ & 23.6 & 2.0 & 14.5 \\
$35-44$ & 14.4 & 4.4 & 10.2 \\
$45-54$ & 8.7 & 1.5 & 5.7 \\
$55-64$ & 3.9 & 0.2 & 2.4 \\
$65-74$ & 2.6 & 0.0 & 1.5 \\
$\geq 75$ & 2.0 & 0.0 & 1.2 \\
\hline
\end{tabular}

Table 2. Distribution of the PCR-positive cases for Influenza A(H1N1) among the study population.

Characteristic age in years Citizens \& residents \% Students \% Total citizens, residents, \& students \%

\begin{tabular}{cccc}
\hline$<5$ & 11.3 & 0.0 & 7.9 \\
$5-9$ & 5.6 & 26.1 & 11.8 \\
$10-14$ & 5.8 & 47.9 & 18.6 \\
$15-24$ & 26.9 & 19.3 & 24.6 \\
$25-34$ & 22.4 & 1.5 & 16.0 \\
$35-44$ & 13.7 & 3.8 & 10.7 \\
$45-54$ & 8.3 & 1.5 & 6.3 \\
$55-64$ & 3.4 & 0.0 & 2.4 \\
$65-74$ & 1.9 & 0.0 & 1.3 \\
$\geq 75$ & 1.0 & 0.0 & 0.5 \\
\hline
\end{tabular}

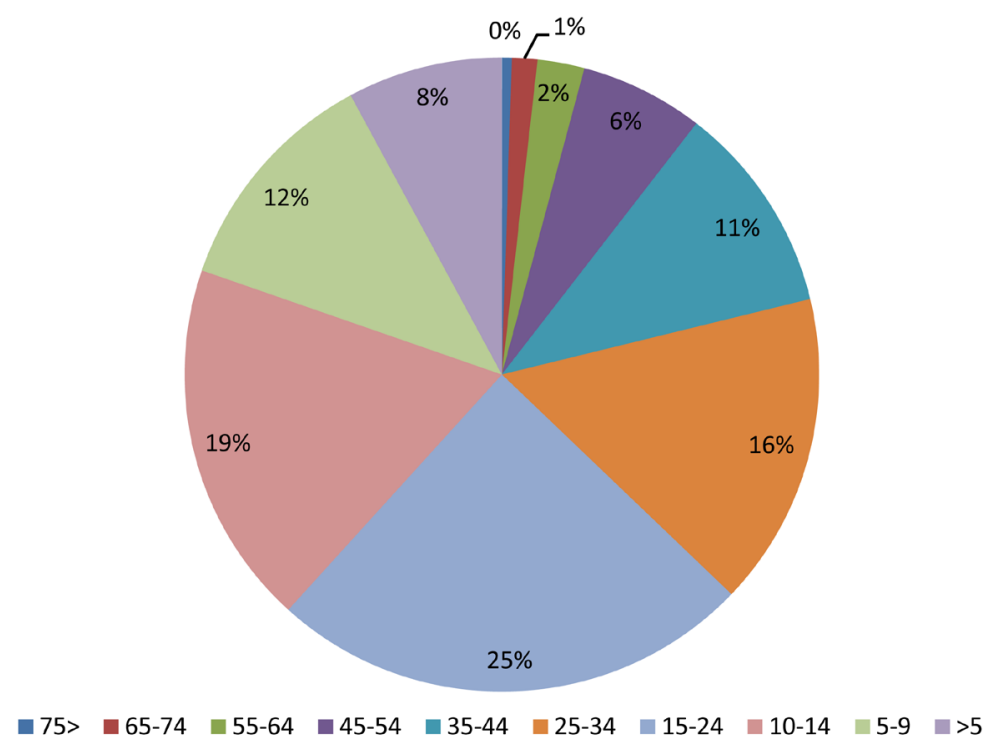

Figure 1. Percentage of PCR-positive cases for Influenza A(H1N1) according to age group. 
Table 3. Distribution of the study population by sex.

\begin{tabular}{cccc}
\hline Characteristic: Sex & Citizens \& residents \% & Students \% & Total citizens, residents, \& students \% \\
\hline Male & 57.6 & 52.3 & 55.4 \\
Female & 42.4 & 47.7 & 44.6 \\
\hline
\end{tabular}

Table 4. Distribution of the PCR-positive cases among study population by sex.

\begin{tabular}{cccc}
\hline Characteristic: Sex & Citizens \& residents \% & Students \% & Total citizens, residents, \& students \% \\
\hline Male & 57.1 & 58.6 & 58.1 \\
Female & 42.9 & 41.4 & 41.9
\end{tabular}

no statistically significant difference in the PCR positivity based on the gender distribution among both the citizen and student groups $(P=0.886)$.

Out of the total study population, $74.9 \%$ were citizens, while the remaining $20.5 \%$ were visitors from different nationalities (Table 5). Among the student subgroups, $85.7 \%$ were citizens, and $14.3 \%$ were non-citizens. The distribution of the PCR-positive cases for Influenza A(H1N1) among study population showed that; the highest positive cases were among citizen and residents as it shown in Table 6.

The highest percentages of PCR-positive cases for Influenza A(H1N1) were seen at primary school levels with $33.3 \%$ frequency for males and $21.8 \%$ for females (Table 7 ). However, at secondary school levels for males and females, these frequencies dropped to $7.0 \%$ and $6.8 \%$, respectively. Intermediate frequency percentages of $17.8 \%$ (males) and $12.3 \%$ (females) were observed at preparatory education levels.

PCR-positive cases for Influenza A(H1N1) primarily among male students presented more than half (52.6\%) of all cases (Figure 2), whereas the percentage among female students was $47.4 \%$. Among male students, Pakistani boys showed the highest percentage (Figure 3), while Egyptian girls showed the highest percentage among female students (Figure 4).

\section{Discussion}

Annual influenza epidemics are estimated to affect $5 \%-15 \%$ of the global population. Although most cases are mild, these epidemics still cause severe illness in 3 - 5 million people and 250,000 - 500,000 deaths worldwide [19]. On average, 41,400 people die each year in the United States based on data collected between 1979 and 2001 [20]. In industrialized countries, severe illness and death occurs mainly in the high-risk populations of infants, the elderly, and the chronically ill [18], although the swine flu outbreak (as well as the 1918 Spanish flu) differs in its tendency to affect younger, healthier people [20].

Influenza is an annual major public health threat. Each year, the influenza vaccine is targeted against the strains (usually from the past year) that are expected to circulate in the next season. However, when a major antigenic shift occurs, time is insufficient to manufacture a vaccine for the first wave of the ensuing pandemic [21] [22]. Since 1977, A(H1N1) strains have been isolated in the United States with varying frequency [23]-[25]. The majority of A(H1N1) isolates in 1984 and 1985 resembled the A/Chile/1/83 strain, and subsequently this antigen was included in the trivalent influenza vaccines for the 1984-1985, 1985-1986, and 1986-1987 influenza seasons [24]-[26]. Swine influenza (also called swine flu, hog flu, pig flu, and sometimes, the swine) is an infection by any one of several types of swine influenza virus (SIV). It is any strain of the influenza family of viruses that is endemic in pigs. As at 2009, the known SIV strains included influenza C and the subtypes of Influenza A known as H1N1, H1N2, H3N1, H3N2, and H2N3 [21].

These strains of swine flu rarely pass from human to human. Symptoms of zoonotic swine flu in humans are similar to those of influenza and of influenza-like illness in general, namely chills, fever, sore throat, muscle pains, severe headache, coughing, weakness, and general discomfort with gastrointestinal symptoms such as vomiting and diarrhea [21] [25] [27].

The results showed that $81 \%$ of the studied population was between 5 and 45 years of age. In the student subgroup, $69 \%$ of subjects belonged in the 10 - 24 years age group. In the study population, $27 \%$ of Influenza A(H1N1)-positive cases were between 15 and 24 years old, while in the student subgroup, 48\% of PCR-positive 
Table 5. Distribution of the study population by nationality.

\begin{tabular}{cccc}
\hline Characteristic: Nationality & Citizens \& residents \% & Students \% & Totalcitizens, residents, \& students \% \\
\hline Citizens & 74.9 & 85.7 & 79.5 \\
Visitors & 25.1 & 14.3 & 20.5 \\
\hline
\end{tabular}

Table 6. Distribution of the study population by nationality.

\begin{tabular}{|c|c|c|c|}
\hline Characteristic: Nationality & Citizens \& Residents \% & Students \% & Total citizens, residents, \& students \% \\
\hline Citizens & $78.8 \%$ & $95.2 \%$ & $83.7 \%$ \\
\hline Visitors & $21.2 \%$ & $4.8 \%$ & $16.3 \%$ \\
\hline
\end{tabular}

Table 7. Distribution of the PCR-positive cases for Influenza A(H1N1) among students by school level of education.

\begin{tabular}{ccc}
\hline & \multicolumn{2}{c}{ Students } \\
Characteristic: School level of education & Males \% & Females \% \\
\cline { 2 - 3 } Nursery schools & 0.5 & 0.5 \\
Primary schools & 33.3 & 21.8 \\
Preparatory schools & 17.8 & 12.3 \\
Secondary & 7.0 & 6.8 \\
Total (\%) & 58.6 & 41.4 \\
\hline
\end{tabular}

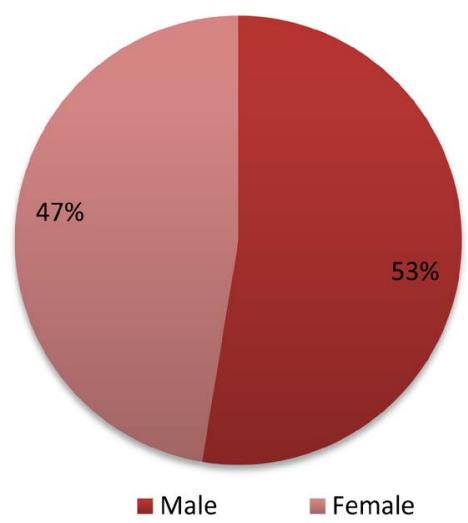

Figure 2. PCR-positive cases for Influenza A(H1N1) for male and female.

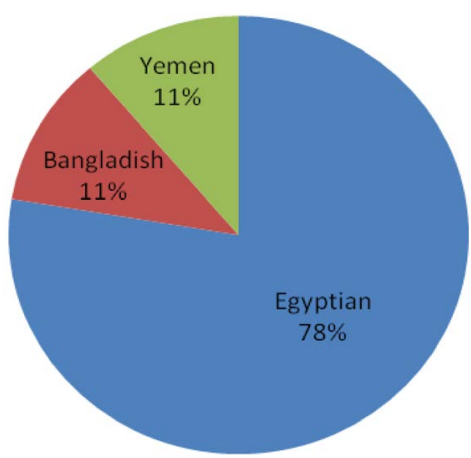

Figure 3. Distribution of the PCR-positive cases for Influenza A(H1N1) among non-citizen students female) by nationality. 


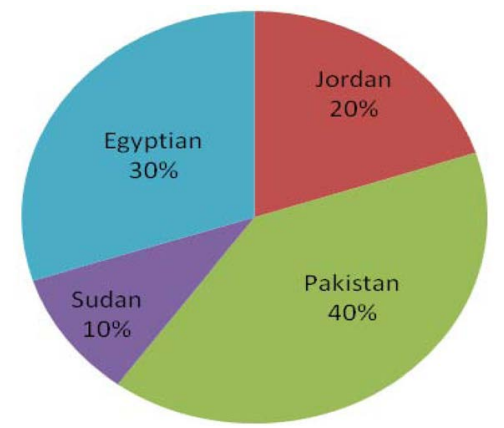

Figure 4. Distribution of the PCR-positive cases for Influenza A(H1N1) among non-Saudi students (males) by nationality.

cases were seen in the primary school stage. The highest percentage (25\%) of PCR-positive cases in citizens/ residents (27\%) and students (19\%) were seen in those between 15 and 24 years of age. Similarly, in a smaller cohort of population studied by Al-Mazroa et al. [28], the highest percentage of the cases were in the age group of 20 - 30 years old followed by the age group of 1 - 10 years old. However, an important factor for the increased incidence of $\mathrm{A}(\mathrm{H} 1 \mathrm{~N} 1)$ cases among the younger population groups may be attributable to increased activity and movement. All positive cases received treatment and recovered completely. In Makkah, school closures were not undertaken based on the criteria of $10 \%$ of cases among students and employees or $10 \%$ absenteeism. We had a strong and effective health education program aimed at the whole community and specifically towards students. Responsibility can also be credited to the good coordination between the departments of health affairs and education.

No school closures were undertaken during the study period. Effective measures taken by Saudi health authorities at all levels played a key role in prevention and control of $\mathrm{A}(\mathrm{H} 1 \mathrm{~N} 1)$ among the residents and students. Previous studies on Hajj pilgrims suggested a high incidence of influenza-related respiratory tract infections with approximately 24,000 cases seen every year [17]. Furthermore, the seasonal influenza vaccination rate among visiting pilgrims was quite low. In order to prevent an emergence of novel influenza viruses during the Hajj event and the year-round Umrah gathering in Makkaha, steps like non-pharmaceutical interventions, enhanced surveillance with screening, ensuring quarantine at the entry points, mandatory vaccination for seasonal flu, and timely provision of diagnostic facilities may be implemented. Health education and public awareness regarding safety precautions including vaccinations may be the best long-term efforts towards effective control of H1N1 influenza.

Further analysis of the information obtained from this study will be important to understand their diversity and evolutionary history in comparison with the swine Influenza A(H1N1) worldwide [29] [30].

\section{Conclusion \& Recommendations}

A total of 1138 subjects, irrespective of age and sex, were included in the study. Among the study population, 25\% of the cases in the age group between 15 and 24 years old were found positive for Influenza A(H1N1) by the PCR technique. Although a significant population was affected by Influenza A(H1N1) during 2009 in Makkah, the efforts and steps taken by health authorities at all levels, especially those in Directorate of Health Affairs of Makkah helped to avert the mortality associated with Influenza A(H1N1) among the residents and those coming for Umra and Hajj to Makkah by providing treatment facilities and timely diagnosis. Because the influenza viruses mutate and produce new strains, we stress the importance of following basic instructions and dissemination the information among the community, which will limit the spread of the disease. This includes the yearly flu vaccination as the first and most important step in protecting against Influenza. Covering the nose and mouth with a tissue when coughing or sneezing, throwing the tissue in the trash after using, and washing the hands often with soap and water is also recommended. If soap and water are not available, the use of an alcohol-based hand rub can be an alternative method, as well as avoiding touching the eyes, nose, and mouth as germs can be spread that way. If someone is getting sick, they should stay home from work or school and limit contact with others to keep from infecting them. Public health advice must be followed regarding school closures, avoiding crowds, and other social distancing measures to reduce or prevent the spread of Influenza. 


\section{Acknowledgements}

The author greatly thanks Mr. Adel Al-Zahrani for PCR sample preparation and Dr. Kamal QamarAlanbia for his suggestions.

\section{Conflict of Interest and Sources of Funding}

There was no financial or other form of conflicts of interest to any of the authors.

\section{References}

[1] Thompson, W., Shay D.K., Weintraub, E., et al. (2003) Mortality Associated with Influenza and Respiratory Syncytial Virus in the United States. JAMA, 289, 179-186. http://dx.doi.org/10.1001/jama.289.2.179

[2] Kilbourne, E.D. (1975) The Influenza Viruses and Influenza. Academic Press, New York.

[3] Beare, A.S., Ed. (1982) Epidemiological and Clinical Aspects of Influenza. Basic and Applied Influenza Research. CRC Press, Inc., Boca Raton, 11-50.

[4] Centers for Disease Control and Prevention, Recommendation of the Immunization Practices Advisory Committee (2009) Monovalent Influenza A(H1N1) Vaccine, 1986-1987. Morbidity and Mortality Weekly Report, 35, 517-521.

[5] Centers for Disease Control and Prevention (1986) Antigenic Variation of Recent Influenza A(H1N1) Viruses. Morbidity and Mortality Weekly Report, 35, 510-512.

[6] Centers for Disease Control and Prevention (1986) Influenza, United States, 1985-1986 Season. Morbidity and Mortality Weekly Report, 35, 470-479.

[7] Centers for Disease Control and Prevention (1986) Update: Influenza Activity—Micronesia, United States. Morbidity and Mortality Weekly Report, 35, 685-687.

[8] Centers for Disease Control and Prevention (2009) Briefing on Investigation of Human Cases of H1N1 Flu. CDC, Atlanta.

[9] Centers for Disease Control and Prevention (2009) Interim Guidance for 2009 H1N1 Flu (Swine Flu). Taking Care of a Sick Person in Your Home.

http://www.communitycounselingservices.org/poc/view_doc.php?type=doc\&id=30115\&cn=342

[10] World Health Organization (2009) Clinical Features of Severe Cases of Pandemic Influenza. WHO, Geneva.

[11] Picard, A. (2009) Reader Questions on H1N1 Answered. The Globe and Mail, Toronto, 1 November 2009.

[12] European Centre for Disease Prevention and Control (2009) Pandemic (H1N1). ECDC Daily Update, 23 November 2009.

[13] Fukuda, K. (2009) Transcript of Virtual Press Conference with Dr. Keiji Fukuda, Assistant Director-General ad Interim for Health Security and Environment, World Health Organization. World Health Organization, 7 July 2009.

[14] Centers for Disease Control and Prevention (2009) Update: Novel Influenza A(H1N1) Virus Infections Worldwide, May 6, 2009. Morbidity and Mortality Weekly Report, 8 May 2009.

[15] Centers for Disease Control and Prevention (2009) H1N1 Flu (Swine Flu). CDC, 30 October 2009.

[16] Centers for Disease Control and Prevention (2009) 2009-2010 Influenza Season Week 43. CDC, 31 October 2009.

[17] The Telegraph, Millions of Muslims Make Hajj Pilgrimage to Mecca. 2 October 2014.

[18] Chan, M. (2009) World Now at the Start of 2009 Influenza Pandemic. World Health Organization.

[19] Centers for Disease Control and Prevention (2009) Division of Diabetes Translation. CDC's Diabetes Program News \& Information-H1N1 Flu. Centers for Disease Control and Prevention, 14 October 2009.

[20] Centers for Disease Control and Prevention (2009) Surveillance for Pediatric Deaths Associated with 2009 Pandemic Influenza A(H1N1) Virus Infection United States, April-August 2009. Morbidity and Mortality Weekly Report, 4 September 2009.

[21] Hartocollis, A. (2009) Underlying Conditions May Add to Flu Worries. The New York Times, 27 May 2009.

[22] World Health Organization (2009) Clinical Features of Severe Cases of Pandemic Influenza. World Health Organization, Geneva, 16 October 2009.

[23] Roan, S. (2009) Masks May Help Prevent Flu, But Aren’t Advised. Chicago Tribune, Tribune Newspapers, 27 September 2009.

[24] George, C. (2009) Schools Revamp Swine Flu Plans for Fall. Houston Chronicle, 31 August 2009.

[25] de Vise, D. (2009) Colleges Warned about Fall Flu Outbreaks on Campus. The Washington Post, 20 August 2009. 
[26] Gardner, A. (2009) Get Smart about Swine Flu for Back-to-School. Atlanta Journal-Constitution, 14 August 2009.

[27] Mehta, S. and Santa Cruz, N. (2009) Swine Flu Goes to Camp. Will It Go to School Next? Los Angeles Times, 27 July 2009.

[28] Al-Mazroa, M.A., Memish, Z.A. and Al-Wadey, A.M. (2010) Pandemic Influenza A(H1N1) in Saudi Arabia: Description of the First One Hundred Cases. Annals of Saudi Medicine, 30, 11-14.

[29] King Jr., J.C. (2009) The ABC’s of H1N1. The New York Times, 1 August 2009.

[30] Dushoff, J., Plotkin, J.B., Viboud, C., Earn, D.J.D. and Simonsen, L. (2006) Mortality Due to Influenza in the United States-An Annualized Regression Approach Using Multiple-Cause Mortality Data. American Journal of Epidemiology, 163, 181-187. http://dx.doi.org/10.1093/aje/kwj024 
Scientific Research Publishing (SCIRP) is one of the largest Open Access journal publishers. It is currently publishing more than 200 open access, online, peer-reviewed journals covering a wide range of academic disciplines. SCIRP serves the worldwide academic communities and contributes to the progress and application of science with its publication.

Other selected journals from SCIRP are listed as below. Submit your manuscript to us via either submit@scirp.org or Online Submission Portal.
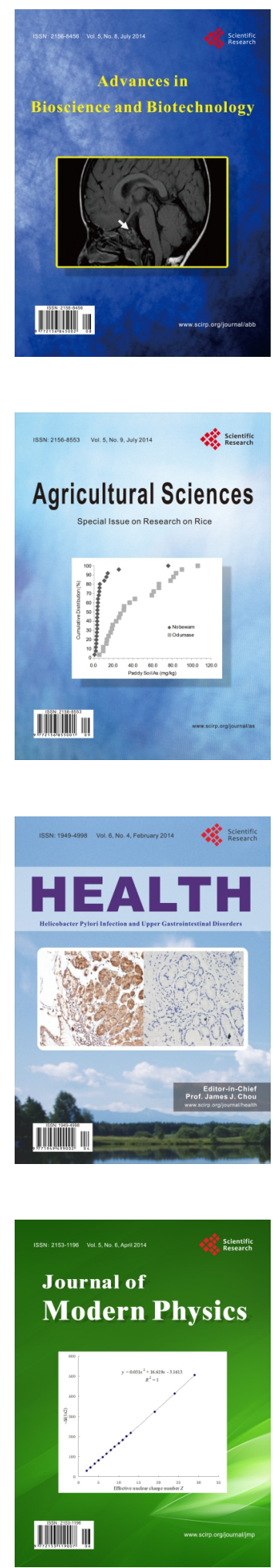
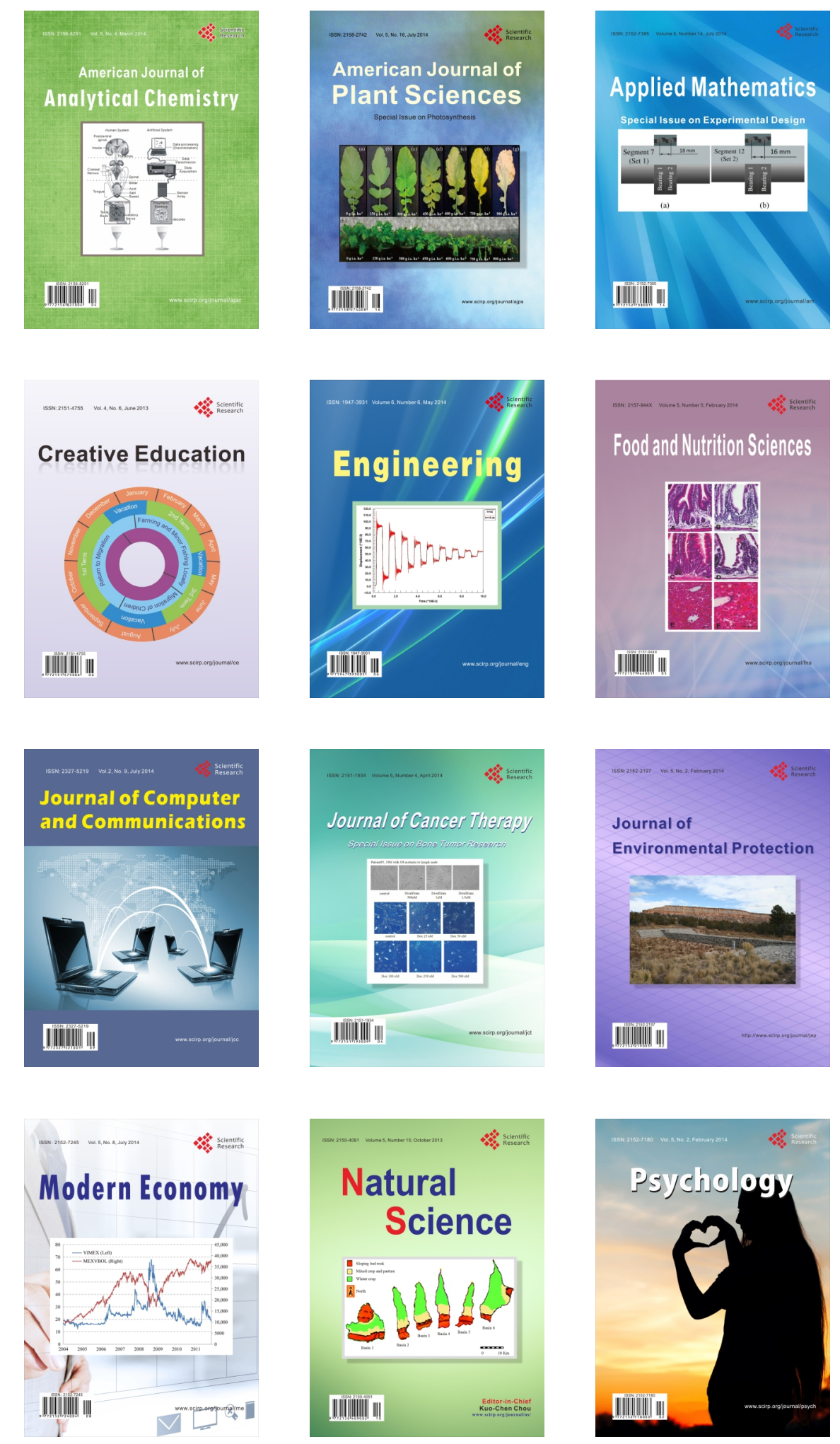